The Overlapping Relationship between Emotion Perception and Theory of Mind

\author{
Rachel L. C. Mitchell \\ King’s College, London \\ Louise H. Phillips \\ University of Aberdeen
}

Author Note

Rachel L. C. Mitchell, Centre for Affective Disorders, King's College, London; Louise H. Phillips, School of Psychology, University of Aberdeen.

Correspondence concerning this article should be addressed to Dr. Rachel Mitchell, Centre for Affective Disorders (PO box 72), Department of Psychological Medicine, Institute of Psychiatry, King’s College London, De Crespigny Park, Denmark Hill. LONDON. SE5 8AF. U.K. Contact: Rachel.Mitchell@kcl.ac.uk. 


\begin{abstract}
Socio-cognitive skills are crucial for successful interpersonal interactions. Two particularly important socio-cognitive processes are emotion perception (EP) and theory of mind (ToM), but agreement is lacking on terminology and conceptual links between these constructs. Here we seek to clarify the relationship between the two at multiple levels, from concept to neuroanatomy. EP is often regarded as a low-level perceptual process necessary to decode affective cues, while ToM is usually seen as a higher-level cognitive process involving mental state deduction. In information processing models, EP tends to precede ToM. At the neuroanatomical level, lesion study data suggest that EP and ToM are both right-hemisphere based, but there is also evidence that ToM requires temporal-cingulate networks, whereas EP requires partially separable regions linked to distinct emotions. Common regions identified in fMRI studies of EP and ToM have included medial prefrontal cortex and temporal lobe areas, but differences emerge depending on the perceptual, cognitive and emotional demands of the EP and ToM tasks. For the future, clarity of definition of EP and ToM will be paramount to produce distinct task manipulations and inform models of sociocognitive processing.
\end{abstract}

Keywords: theory of mind, emotion perception, social cognition, mentalising, social brain

Word Count: 7,155 


\section{On the Relationship between Emotion Perception and Theory of Mind}

Cross-fertilisation from the traditionally separate disciplines of social psychology and cognitive neuropsychology in recent years has arguably been one of the most fruitful developments in the study of the human mind and behaviour, and has culminated in an explosion of research on socio-cognitive neuroscience. Social cognition is defined in various ways, but generally refers to the mental operations that underlie social interactions, including perceiving, interpreting, and generating responses to the intentions, dispositions, and behaviours of others (Green, et al., 2008). Its importance to human existence is well documented. Indeed, the complex and well-developed nature of human social activity has been argued to be the primary selective evolutionary pressure for the extraordinary size and complexity of the human brain: the "social brain” hypothesis (Adolphs, 2009).

'Social cognition’ is actually an umbrella term that reflects a broad variety of psychological processes (Yager \& Ehmann, 2006). In this review, we focus on two particular aspects namely 'theory of mind', and 'emotion perception'. Whilst their definitions are debated (see section 2), the working definition of emotion perception (EP) that we adopted for this review was the identification of emotionally salient information in the environment, i.e. verbal (lexico-semantic) and nonverbal (intonational, facial, visual and body movement) cues to the emotions of other people (M. L. Phillips, 2003). The working definition of theory of mind (ToM) that we adopted was the ability to infer and predict the intentions, thoughts, desires, intuitions, behavioural reactions, plans and beliefs of other people (C. D. Frith \& Frith, 2011; Green, et al., 2008; Mathersul, McDonald, \& Rushby, 2013), through an awareness that others have a mind with mental states, information and motivations that may differ from one’s own (Korkmaz, 2011; Sabbagh, 2004). The processes that comprise theory of mind thus include the abilities to shift (i.e. engage and disengage attention from different task sets), update (i.e. monitor and code information and replace old non-relevant information with new relevant information), and inhibit (i.e. hold back preponderant or automatic 
responses when necessary) (Aboulafia-Brakha, Christe, Martory, \& Annoni, 2011). Thus to demonstrate theory of mind, one has to be able to represent cognitive and affective mental states, attribute these mental states to self and other, and deploy these mental states in a manner that allows one to correctly understand and predict behaviour (Abu-Akel \& Shamay-Tsoory, 2011; Hillis, 2014). In current literature, EP and ToM are sometimes discussed as two parts of a general ability ( e.g. Adolphs, 2003), sometimes as two separate abilities (e.g. Blair, 2005), and sometimes EP is described as a precursor to ToM (Beer \& Ochsner, 2006; Chakrabarti \& Baron-Cohen, 2006). At best this is confusing, but at its worst, it may be limiting the progression of this important field of research. Terminology is not always used in a consistent manner, and it is not always easy to determine researchers' theoretical assumptions about how EP and ToM relate to each other. The models reviewed in section 3, evidence areas of disagreement. Accordingly, the aims of this review were to examine the convergence and divergence of these two cognitive processes, and to better understand the nature of their relationship at the conceptual, cognitive and neuroanatomical levels.

In the next section, we introduce the relevant terminology and concepts. At the conceptual level, the patterns of relationship that one might look for could include EP and ToM being a specialist form of the other, or being qualitatively different. We then go on to briefly review prominent theoretical models of social cognition. In these models, overlap between EP and ToM could also take several forms, including EP being a serial precursor to ToM, ToM being necessary for understanding emotional states, or there being a social cognition 'module' capable of processing both emotion and ToM cues in parallel. Next we consider the overlap in the neural circuits that subserve EP and ToM, first by reviewing neuropsychological evidence of the effects of localised brain lesions on EP and ToM. The highest level of evidence for a non-overlapping relationship would come from a double dissociation, in which damage to brain region 'A' impaired EP but not ToM, with damage to region 'B' impairing ToM but not EP. We also review the evidence of 
dissociations and overlaps in the neural circuitry between EP and ToM from neuroimaging evidence in healthy young adults.

\section{Definitions, Distinctions and Models.}

Starting at the most basic level of analysis, we soon arrive at a particularly taxing issue, namely the confusing terminology used to define EP and ToM. The concepts and terminology differ considerably from one author to the next. In some cases, EP and ToM are seen as different facets of a shared core concept (L. H. Phillips, MacLean, \& Allen, 2002), such as 'emotional intelligence’ (Mayer \& Salovey, 1997). However, there are other instances where EP and ToM are treated as separate entities (McDonald, et al., 2006) which are independent aspects of social cognition. There are numerous theories in the literature about the way in which EP and ToM are related. Two key dimensions which emerge from that literature are the distinction between 'hot' v 'cold' social cognition, and the level of processing, i.e. perceptual representation of social cues $\mathrm{v}$ interpretation and reasoning about social information. Below we summarise some of the major models in the field, starting with those that focus on the distinction between hot and cold social processing (see also Table 1a), and then reviewing those that focus on the complexity of processing involved (see Table 1b).

Many authors have proposed that different mechanisms are needed to process emotional and non-emotional interpersonal information (see Table 1a). For example, Blair (2005) and ShamayTsoory et al. (Shamay-Tsoory, et al., 2007; Shamay-Tsoory, Tomer, Berger, \& Aharon-Peretz, 2003; Shamay-Tsoory, Tomer, Goldsher, Berger, \& Aharon-Peretz, 2004) differentiate cognitive from emotional empathy, empathy being the skill that allows individuals to share the affective states of others, predict others' actions, and stimulate pro-social behaviour (Gonzalez-Liencres, ShamayTsoory, \& Brune, 2013). Here, it is suggested that cognitive empathy reflects the representation of the internal mental state of others, which is in effect ToM. In contrast, emotional empathy reflects 
the response to the emotional displays of others, which is dependent on EP (Blair, 2005; ShamayTsoory, et al., 2007; Shamay-Tsoory, et al., 2003; Shamay-Tsoory, et al., 2004). Similarly Brothers and Ring contrasted 'cold' and 'hot' ToM (Brothers \& Ring, 1992), the former being a more cognitive process, and the latter being a more emotional process. So, EP and ToM have sometimes been distinguished according to the type of information being processed, namely understanding emotions vs. understanding beliefs and intentions.

Another important distinction is between low-level perceptual processes necessary to decode social information from the environment, and higher-level cognitive processes which integrate and interpret cues to emotions and intentions. Some of the key theories proposing this distinction are shown in Table 1b. One of the foremost models of how EP and ToM relate - the Mindreading System - is primarily derived from research on autism (Baron-Cohen, 1994) Baron-Cohen, 2005; Chakrabarti \& Baron-Cohen, 2006). In this model, EP and (cognitive) ToM are seen as different components of the system that subserves the overall ability to perceive and respond appropriately to the emotions and intentions of others (Decety, 2010). There are three key perceptual components which detect relevant social cues: an Intentionality Detector to pick up mental states such as goals and desires, the Eye Direction Detector, to assess where others are looking in the environment, and the Emotion Detector - the key component in emotion perception. In addition there is a Shared Attention Mechanism which supports the ability to selectively attend to objects that are mutually interesting. Finally there are higher level Theory of Mind and Empathy Mechanisms. The Emotion Detector and other precursors are considered to be basic perceptual processes which feed into the Shared Attention Mechanism, which then acts to integrate different social cues. This attention mechanism acts as a 'gateway' to the more advanced ability of ToM. EP therefore precedes ToM, both in terms of processing mechanisms and timecourse. The system's overall purpose of perceiving and responding appropriately to the emotions and intentions of others is in line with ToM having both cognitive and affective forms. 
Corrigan (e.g. 1997) proposed a model of social cognition which is cognitive in origin, and arose from research on information-processing deficits in schizophrenia (Corrigan, 1997). This model divides social cognition into several discrete processing functions that relate serially; it is a bottom-up model: emotion cues are perceived from undifferentiated social stimuli in the environment, encoded, and then passed to the memory system, for higher-order processing, which corresponds to ToM. In this model, social cognition is not treated as a single specialised module, rather it reflects a consortium of specialised cognitive processes, each of which solves some circumscribed aspect of the need to determine other people’s beliefs and intentions (J. P. Mitchell, 2006). EP always precedes ToM in the processing chain, and ToM cannot proceed without input from EP.

Also described as a 'processing stream' is the approach of Ochsner et al., who describes human social and emotional behaviour as being highly intertwined (Beer \& Ochsner, 2006).. In their model, the five core constructs are: (i) Acquisition of social-emotional values and responses, which leads to (ii) Recognising and responding to social-emotional stimuli, which then leads to either (iii) Low-level mental state inference, (iv) High-level mental state/trait inference, or (v) Context-sensitive regulation (Ochsner, 2008). EP takes place at stage 2, and ToM takes place at stage 4. Yet, it is argued that the ability to understand the emotional states crucially depends on ToM because, by definition, understanding requires a causal attribution about the intentions behind an action.

In most of these conceptual models, we have seen that EP (or at least the detection of emotion cues) is thought to precede ToM, however, EP features more prominently in some models than in others. The suggestion that EP occurs at an earlier temporal stage compared to ToM is most apparent in the information-processing models (Corrigan, 1997; J. P. Mitchell, 2006). There may however, be supplementary top-down mechanisms whereby ToM can influence EP, e.g. via longterm knowledge. Most of the conceptual models reviewed here therefore give the impression that EP and ToM are indeed related, because EP is a precursor to the more advanced function of ToM. 
Sabbagh also distinguishes between the ability to decode others' mental states from immediately available observable cues, vs. the ability to reason about those mental states to explain or predict others' actions (Sabbagh, 2004). In the past, decoding has often been conflated with EP, and reasoning with ToM. However, this may not always be appropriate, since basic decoding mechanisms can specialise for either emotional information (e.g. detecting key indicators of emotion from facial expression), or intentional information (e.g. detecting agency from biological motion, detecting eye gaze as an indicator of attention). Further, some tasks such as the integration of eye-gaze and facial emotion cues, require the perception and combination of both emotional and intentional information (Adams \& Kleck, 2005). Higher-level reasoning processes can also be specific to emotional information (e.g. weighing up which verbal label best describes an emotional expression), not just for intentional information (e.g. understanding that someone holds a false belief about a situation). However, it is also likely that social reasoning will sometimes require the integration of multiple emotional and intentional cues, e.g. when trying to decode sarcasm or deception.

In order to draw together some of the key distinctions in these models of social cognition we outline a two dimensional model in Table 2 which shows both the hot v cold distinction and the low-level perception v high-level conceptual processing distinction. In this table we also give examples of the kinds of tasks which fit these categories, though note that this is not intended to be an exhaustive list of all possible social cognition tasks. Emotion perception has been used to describe any of the processes involved in understanding affect described in the top row of the table. This highlights one of the difficulties in this area: that the term 'emotion perception' is often used to describe quite different levels of task: from the basic detection of an emotional cue up to the interpretation and verbal labelling of such cues. Some tasks traditionally described as 'emotion perception' (e.g. choosing verbal labels to describe facial expression of emotion) in fact require quite complex cognitive decision-making processes (L. H. Phillips, Channon, Tunstall, Hedenstrom, \& Lyons, 2008). Also, the term 'theory of mind' covers a broad range of the potential 
tasks listed in the table. Traditionally, theory of mind has been used as a description of higher-level cognitive processes involved in reasoning about mental states (corresponding to the false belief tasks assessing high-level cognition in Table 2). Many ToM tasks also assess the integration of cognitive and emotional information about others, such as the widely used Strange Stories task (F. G. Happe, 1994) or Faux Pas test (Stone, Baron-Cohen, \& Knight, 1998). Sometimes ToM is used as an umbrella term to cover almost all of the processes described in Table 2, under the general term 'mentalising'. However, usually basic perceptual processes such as gaze detection are seen as 'precursors’ to full mental state understanding (e.g. in Baron-Cohen’s model of ToM).

In many everyday situations it is likely that both affective and cognitive processing will be necessary for social cognition, and both low-level detection and higher level reasoning processes. For example, understanding complex social emotions such as guilt, shame, and embarrassment, or intentional states such as deception and sarcasm, likely includes both emotional and intentional components: this corresponds to the final box in Table 2. This integrated decoding of emotion and intention can be seen in one of the more widely used ToM tasks, namely Baron-Cohen’s 'Reading the Mind in the Eyes’ task (Baron-Cohen, Jolliffe, Mortimore, \& Robertson, 1997). In this task, participants have to choose between different labels to describe pictures of eyes, from options that combine both emotional and intentional components, e.g. choose which of four words best describes what the person is thinking or feeling from 'reflective', 'aghast', 'irritated' and 'impatient'. This task has been described as both a measure of EP (Adolphs, Baron-Cohen, \& Tranel, 2002) and ToM (Baron-Cohen, Wheelwright, Hill, Raste, \& Plumb, 2001), indicating a likely point of interface between the two concepts.

Understanding the way that EP and ToM relate to each other is complicated by inconsistent and under-specified uses of relevant terminology. There is a clear distinction between 'emotion perception' when it is simply used to describe the low-level perceptual processes needed to organise sensory stimulation (Shany-Ur \& Rankin, 2011) and 'theory of mind' when it is used to describe the 
complete set of cognitive mentalising skills (McDonald, 2013). However, there is much more conceptual overlap when the term 'emotion perception' is used to describe more advanced processing such as the comprehension or understanding of emotion cues and the ability to make inferences from such cues (Hassel, et al., 2009; Kucharska-Pietura \& Mortimer, 2013). 'Theory of mind' is also sometimes used to refer to mentalising about affective intentions and beliefs (McKinnon, Cusi, \& MacQueen, 2013). With such broad definitions of ‘emotion perception’ and 'theory of mind', substantial overlap between the two processes is implied (Cusi, Nazarov, Holshausen, Macqueen, \& McKinnon, 2012).

Some of these problems can be reconciled if we take on board the fact that EP and ToM are in fact multi-factorial constructs, comprised of multiple sub-processes, as suggested in Table 2. EP and ToM are both likely to be involved in understanding complex mental states such as sarcasm or faux pas, whilst analysing simpler cues to emotion or intention may tap solely EP or ToM. Certain

low-level perceptual processes are sometimes portrayed as defining EP, whilst other more advanced cognitive evaluations are often portrayed as defining ToM. One recommendation for ensuring greater consistency in the literature is therefore for researchers to be precise about the temporal stage of EP or subtype of ToM that they are referring to. Thus standard adoption of qualifying terms like cognitive ToM or affective ToM would seem prudent (Poletti, Enrici, \& Adenzato, 2012). Wherever possible in the literature reviewed below, we add these qualifiers in brackets, to help the reader discern precisely what is being referred to.

\section{Lesion Study Data on the Relationship Between Emotion Perception and Theory of Mind}

The first set of evidence that we shall consider on the neuroanatomical relationship between EP and ToM comes from studying the effects of localised brain lesions. To orient the reader, focussed literature on the neurology of EP has suggested a number of key themes, namely that EP as a whole may be right-lateralised (J. C. Borod, Bloom, Brickman, Nakhutina, \& Curko, 2002; 
Yuvaraj, Murugappan, Norlinah, Sundaraj, \& Khairiyah, 2013), or that it may be lateralised according to valence with the right hemisphere being responsible for the perception of negative emotions and the left hemisphere being important for perceiving positive emotions (Ahern \& Schwartz, 1979; Davidson, Mednick, Moss, Saron, \& Schaffer, 1987). Both the right-hemisphere and valence hypotheses have, however, been contested (Abbott, Wijeratne, Hughes, Perre, \& Lindell, 2014). Right hemisphere lateralisation of emotional prosody perception to match that suggested for facial emotion perception has also been mooted (J. C. Borod, et al., 2002; Pell, 2006; Ross \& Monnot, 2011), but similarly contested (Witteman, van Ijzendoorn, van de Velde, van Heuven, \& Schiller, 2011). There is also evidence for the recognition of specific emotions being impaired by damage to specific brain regions, with the association between amygdala damage and impaired fear perception and that between insula damage and impaired disgust recognition being particularly prominent (M. L. Phillips, Drevets, Rauch, \& Lane, 2003). Focussed reviews of the neurology of theory of mind suggest that in particular, it is damage to the medial prefrontal cortex (Hillis, 2014; Shamay-Tsoory, 2011), temporo-parietal junction (Abu-Akel, 2003b; Samson, 2009a) that impairs ToM. However, there exist a number of complicating factors include the precise facet of ToM examined and demand for executive function, because of which the interested reader is referred to more detailed reviews elsewhere (Apperly, Samson, \& Humphreys, 2005, 2009; MartinRodriguez \& Leon-Carrion, 2010).

Taken together, comparative studies of the effects of localised brain lesions suggest that there are some commonalities in the neural mechanisms behind EP and ToM. First, we consider examples of direct comparisons of the neurology of EP and ToM through case studies. Patient "HY” had lived in a persistent vegetative state for 6 months after the onset of encephalitis age 10, and although he began a dramatic recovery at age 17, he was left with brain damage highly suggestive of amygdala impairment (Goukon, Noguchi, \& Hosokawa, 2007). In line with previous demonstrations of an association between amygdala function and recognition of fearful facial 
expressions (Adolphs, Tranel, Damasio, \& Damasio, 1994; Morris, et al., 1996), HY showed a significant deficit in recognising this emotion. Goukon et al. (2007) went on to suggest that EP may not play an important role in the neural systems supporting ToM, since this patient's ToM abilities had been near normal since age 22. The implication is that EP may not necessarily be required for ToM, i.e. the two processes may exhibit some neurological independence. Of course, that demonstration was only of a single dissociation. In three patients with medial frontal damage including the anterior cingulate, a stronger dissociation between EP and ToM was teased out (Baird, et al., 2006). EP impairment (again selective for fear) was evident in one of the patients with a unilateral right anterior cingulate lesion, yet (cognitive) ToM was intact in both patients with unilateral right anterior cingulate lesions. In contrast, (cognitive) ToM was impaired in the patient with a bilateral anterior cingulate lesion, and EP was intact. Thus the neuroanatomy of EP and ToM were at least somewhat dissociable, according to laterality. However, in both cases these findings are restricted to one emotional valence only, not to the generic inter-relation of EP and ToM. Neither does the evidence reflect the perfect double-dissociation which might have been achieved if EP were impaired by right cingulate damage and (cognitive) ToM by left cingulate damage.

In relation to functional laterality more generally, the most prominent proposal has been that both ToM and EP are linked to right hemisphere damage. Many studies of stroke patients indicate right hemisphere dominance for EP (Blonder, Bowers, \& Heilman, 1991; J. C. Borod, et al., 1998; J.C. Borod, Koff, Perlman, \& Nicholas, 1986; Charbonneau, Scherzer, Aspirot, \& Cohen, 2003; Zgaljardic, Borod, \& Sliwinski, 2002). However, several studies have also indicated that left hemisphere lesions can sometimes result in impaired EP (Braun, Traue, Frisch, Deighton, \& Kessler, 2005; Mandal, Mohanty, Pandey, \& Mohanty, 1996). For ToM, some previous studies have reported that right hemisphere damage impairs (cognitive) ToM more than left hemisphere damage (Griffin, et al., 2006; F. Happe, Brownell, \& Winner, 1999; Siegal, Carrington, \& Radel, 1996; Winner, Brownell, Happe, Blum, \& Pincus, 1998). However, the pragmatic language 
difficulties that sometimes occur after right hemisphere stroke (Martin \& McDonald, 2003) may influence performance on ToM tasks, which can sometimes be complex linguistically. Other studies have indicated impaired (cognitive) ToM following both left and right hemisphere damage (Surian \& Siegal, 2001; Tompkins, Scharp, Fassbinder, Meigh, \& Armstrong, 2008). The perception of emotion cues from auditory modalities such as prosody is often right-lateralised (R. L. C. Mitchell, Elliott, Barry, Cruttenden, \& Woodruff, 2003; Ross, 2010), and might give rise to even greater overlap with ToM than EP for facial or lexico-semantic cues.

An alternative proposal has been that ToM is associated with intact right hemisphere function, but that EP is not. Supportive evidence for this view arises from patients with right hemisphere brain damage whose performance indicated second-order ToM was impaired, but the rating of emotion intensity in the very same cartoon material was not affected (Griffin, et al., 2006). Patients D.B. and P.F. who both suffered right hemisphere brain damage, showed similar patterns of performance in which their EP was intact, but ToM was not (Njomboro, Deb, \& Humphreys, 2008). However, it is notable in the case of the latter study that the ToM and EP tests used were not matched in any sense and may therefore not necessarily have been of comparable difficulty. In both these studies, the claim that only ToM is right-lateralised is weakened further by lack of comparison to patients with left hemisphere brain damage. Complicating the assessment of a common lateralisation for EP and ToM, is the aforementioned evidence that the lateralisation of EP may depend on the valence of the emotion (Ahern \& Schwartz, 1979; Davidson, et al., 1987). If neither EP nor ToM is actually clearly lateralised, then the claim that both processes share right-hemisphere lateralisation is even less tenable. Neither do EP and ToM appear to demonstrate differential lateralisation consistently. Whereas differential lateralisation of cognitive processes to opposing cerebral hemispheres may enhance the ability to perform two tasks simultaneously (Rogers, 2005), this is not the way the human brain has evolved for ToM vs. EP. This could be because it is not necessary to perform both EP and ToM simultaneously e.g. because EP precedes ToM, or because 
we are so adept at performing EP and ToM simultaneously that enhancement by differential lateralisation is not necessary.

Complicating lateralisation studies is the issue that the intra-hemispheric regions affected by the left or right hemisphere damage often vary between studies. Thus other research has focussed more specifically on the particular brain regions that mediate EP and ToM. If lesions to the same brain regions impact on performance of both EP and ToM, then it is more likely that the two processes reflect overlapping constructs. When considering EP and ToM as unitary functions, the evidence does not support a simple shared neural mapping though. One of the issues raised by these more focused studies is the possibility of different prefrontal cortex (PFC) regions being involved in EP and ToM. For example, it has been claimed that damage to the right ventromedial region is associated with impaired complex ToM i.e. faux paus recognition, but that no distinctions could be made between the performance of groups with ventromedial vs. dorsolateral PFC damage for EP (Shamay-Tsoory, et al., 2003). However, as seen in section 2, neither EP nor ToM is a unitary construct, and comparison of performance on a single EP task and a single ToM task is unlikely to capture the true range of similarities and differences between these multi-factorial multi-stage processes.

From the evidence above, it seems that the most likely differential locus for EP vs. ToM lies in the medial PFC, probably in the right hemisphere. However valence-dependent variations in functional neuroanatomy for EP may be a major source of differences between studies. Although lesion studies can be used to draw powerful conclusions about the critical functional neuroanatomy of socio-cognitive tasks, they only suggest those brain regions necessary for a task, not those that are sufficient or incidentally involved. Further, lesions often lead to compensatory reorganisation, and their foci may spread across diffuse regions (Pascual-Leone, Bartres-Faz, \& Keenan, 1999), meaning that it is not always straightforward to interpret the results of these studies. In the next 
section, we will therefore consider the neuroanatomical separability of EP and ToM from a further perspective, using functional neuroimaging.

\section{Neuroimaging Data on the Relationship Between Emotion Perception and Theory of Mind}

In the literature on the functional neuroanatomy of healthy young adults (largely neuroimaging studies), there has often been speculation of a partial overlap in the neural systems for EP and ToM. In the discussion that follows, where available, we include the corresponding Brodmann's areas, to facilitate localisation. Figure 1 may be useful to the reader in understanding the terminology used to parcellate the frontal lobe. It also displays the Brodmann's areas of relevance to studies which have compared the neuroanatomical relationship between EP and ToM. We focus our discussion on studies that have compared the perception/understanding of affective cues against the inference of thoughts, intentions and beliefs. Thus it does not set out to be a review of the functional neuroanatomy of EP or ToM per se. For these purposes, the reader is referred to several particularly informative reviews in recent years: Theory of mind (Carrington \& Bailey, 2009; Mar, 2011; Martin-Rodriguez \& Leon-Carrion, 2010); Emotion perception (Fossati, 2012; Fusar-Poli, et al., 2009; Phan, Wager, Taylor, \& Liberzon, 2002; M. L. Phillips, et al., 2003). However, some of the key features of this literature are summarised in the next paragraph. An overlap between the functional neuroanatomy of EP and ToM would imply that the concepts are indeed related and as we shall see, there are important ways in which the neural systems for EP and ToM do overlap.

Initial clues as to the relationship between ToM and EP may be drawn from qualitatively comparing the separate meta-analyses and reviews relating to these processes. The brain regions consistently implicated in ToM include the medial PFC (BA 9), the temporo-parietal junction/superior temporal sulcus (BA 39/40/22) and the temporal poles (BA 38) (Carrington \& Bailey, 2009; Saxe, Carey, \& Kanwisher, 2004), the latter two being multimodal sensory 
convergence zones with limbic connections (C. D. Frith \& Frith, 2006; U. Frith \& Frith, 2003). The involvement of these regions is so common for ToM across different studies and tasks, that one might expect their activation regardless of whether the information being processed was affective or non-affective. For EP, the functional neuroanatomy literature is less clear. Medial PFC (BA 9/10) is said to have a general role in EP (Phan, et al., 2002). The amygdala and lateral PFC are also proposed as having such a role, but with the clarification that sensory cortices and ventrolateral PFC mediate stimulus evaluation more specifically (Lee \& Siegle, 2009). However, the superior temporal sulcus may be an equally likely candidate for representing facial emotion cues (Said, Haxby, \& Todorov, 2011), and the amygdala may play an important role in EP through its ability to modulate vigilance and attention to emotionally salient information (Heberlein \& Adolphs, 2004; M. L. Phillips, et al., 2003).

An added complexity to the functional neuroanatomy of EP is that there is also an element of valence-dependence. For example, happy expressions are thought to activate the dorsal anterior cingulate/amygdala, sad expressions activate the subgenual anterior cingulate/amygdala, fearful expressions the amygdala, angry expressions the orbitofrontal cortex/insula, with expressions of disgust activating the insula (Fusar-Poli, et al., 2009; Hamann, 2012; Phan, et al., 2002; Phan, Wager, Taylor, \& Liberzon, 2004; M. L. Phillips, et al., 2003). As for ToM, the EP system also seems to incorporate a supramodal element though, in which medial PFC and superior temporal sulcus regions are often activated whether the cues come from the facial, bodily or vocal channel (Peelen, Atkinson, \& Vuilleumier, 2010; Skerry \& Saxe, 2014). A common early processing stage where social relevance is appraised by the amygdala may also occur irrespective of valence (Garvert, Friston, Dolan, \& Garrido, 2014). Within the ToM literature, there are similar hypotheses about which components are mediated by which particular brain regions (Abu-Akel, 2003a; C. D. Frith \& Frith, 2006; U. Frith \& Frith, 2003; Saxe, et al., 2004; Siegal \& Varley, 2002). In summary, comparison of the functional neuroanatomy for EP and ToM suggests that medial PFC (including 
the anterior cingulate cortex) is one of the most likely points of overlap between the systems (AbuAkel, 2003a; U. Frith \& Frith, 2003), a suggestion supported by comparable evidence from lesion studies (Samson, 2009b). Other likely points of interface include the superior temporal sulcus region for its role in inferring perceptions (Saxe, et al., 2004), and the amygdala for its role in determining emotional significance which would be important for inferring emotion-based intentions (Siegal \& Varley, 2002).

Two particular regions speculated as being involved in both EP and ToM are the dorsomedial PFC and temporal pole (the anterior temporal lobe). During a task requiring participants to judge the appropriateness of specific facial emotions, fMRI data revealed bilateral activation of dorsomedial PFC (BA 8) (Kim, et al., 2005). Since this region is known for its prominent role in ToM regardless of perceptual modality (C. D. Frith \& Frith, 2006), the authors inferred there might be an overlapping arrangement between the processing mechanisms for emotion and theory of mind cues. A similar argument has been made that dorsomedial PFC activity (BA 8) during prosodic emotion identification reflects similar neuroanatomical networks for EP and ToM (Beaucousin, et al., 2006). However, both these inferences constitute 'reverse inferences' in which a cognitive process (ToM in our case) is inferred from neuroimaging data (Poldrack, 2011). More direct forms of evidence do exist (see below), although they do not tend to favour this particular PFC region as being the site of overlap for the EP and ToM systems. The paralimbic temporal pole has also been speculated as a site of integration between the two systems, based on its apparent involvement in facial emotion processing and inferring thoughts or beliefs (Olson, Plotzker, \& Ezzyat, 2007). Nevertheless, these interesting speculations on the possible overlap between EP and ToM are tentative, and without empirical support from primary data.

In experimental work that has explicitly assessed the neuroanatomical links between EP and ToM, the relationship between the two processes appears to be a little more complex. During fMRI evaluation of the mechanisms associated with passively viewing simple facial emotion cues 
(happiness, anger, sadness and disgust), it was observed that the degree of inferior frontal gyrus activation (left dorsolateral PFC - BA 44/46) correlated positively with participants’ scores on an offline questionnaire index of the ability to tune into protagonists' affective state of mind, and have an emotional reaction to it (Chakrabarti, Bullmore, \& Baron-Cohen, 2006). A particularly important part of this ability is the affective ToM component (Blair, 2005). Put simply, the better a person was at tuning into protagonists' likely affective state of mind, the greater the activity in this brain region during EP. Although correlational in nature, this finding provides a strong hint of a neural link between the mechanisms for EP and ToM, at least for affective ToM.

Given that the social cognition models reviewed in section 2 tend to suggest that EP either precedes ToM, or that it occurs in parallel with ToM (Baron-Cohen, 2005; Beer \& Ochsner, 2006; Brothers, 1995, 1997; Chakrabarti \& Baron-Cohen, 2006; C. D. Frith \& Frith, 2006; U. Frith \& Frith, 2003), it is perhaps unlikely that being good at ToM causes greater neural reactivity during EP. Remarkably similar findings to those observed for the facial emotion modality have been observed in the prosodic emotion modality though. In this research, participants' offline score on a questionnaire index of the ability to tune into affective states of mind and have an appropriate emotional reaction, also correlated with activity in the inferior frontal gyrus (albeit in a more ventro-lateral PFC region) during EP (Aziz-Zadeh, Sheng, \& Gheytanchi, 2010). Cross-modality consistencies certainly strengthen the argument for overlapping function in this region. Indeed, it is particularly illuminating that these studies indicate the inferior frontal gyrus as a site of overlap between EP and affective ToM in particular, given its cross-modality role in emotion perception (Sabatinelli, et al., 2011), and its role in social decision making (Grecucci, Giorgetta, Bonini, \& Sanfey, 2013; Grecucci, Giorgetta, Van't Wout, Bonini, \& Sanfey, 2013). Given that the inferior frontal gyrus is thought to become involved in theory of mind relatively late on in the processing sequence (McCleery, Surtees, Graham, Richards, \& Apperly, 2011; Thirioux, Mercier, Blanke, \& 
Berthoz, 2014), it seems most likely that overlap with EP in this region concerns the later 'postperception' (i.e. more cognitive) processing stages.

Other research has directly compared the neuroanatomy of affective vs. cognitive ToM. Given that by definition, affective ToM necessarily includes the perception of emotionally relevant cues, this comparison provides another useful (albeit indirect) means of ascertaining overlap between the neural systems for EP and ToM. Methodologically, altering task instructions whilst keeping the experimental stimuli constant is one means by which affective vs. non-affective ToM perspectives can be manipulated (e.g. 'what are the characters thinking’ vs. 'what are they feeling'). One study that used such a manipulation during fMRI highlighted a differential response in ventral prefrontal regions of the brain in particular, with affective ToM inducing greater activation of ventromedial PFC (BA 11, 47 \& 25) compared to non-affective ToM (Hynes, Baird, \& Grafton, 2006). In this same study, common areas of activation across cognitive and affective ToM were observed in medial PFC (BA 9 \& 10) and in the temporo-parietal region (BA $39 \& 22$ ). The differential effect in ventromedial PFC is perhaps to be expected given its generic role in processing socially relevant stimuli (Fossati, 2012), however, its differential association with affective vs. cognitive ToM is not one repeated in later studies. Comparable methodology in a second study suggested that affective ToM in particular, activated a region bordering the temporo-parietal junction (BA 40) and mid- and anterior cingulate regions (BA 24/23 and BA 24 respectively) (Bodden, et al., 2013). In these results, it is difficult to explain though why an affective ToM task should activate the classic temporo-parietal junction ToM region more than cognitive ToM itself, given that in these classic studies ToM tasks were cognitive in nature (Decety \& Lamm, 2007). However, greater activity in cingulate regions during affective ToM does make sense given its generic role in emotion processing (Etkin, Egner, \& Kalisch, 2011).

Methodology that presents written scenarios (e.g. 'she thinks that the door is open' = belief perception vs. 'she is afraid that the door is open' = emotion perception) followed by yes/no 
questions (e.g. 'does she think that the door is open?' vs. 'does she think that the window is open?', has suggested a double dissociation in which EP recruits the right superior temporal gyrus, but belief perception recruits dorsolateral PFC (BA 9) and the middle temporal gyrus (Zaitchik, et al., 2010). Executive control from dorsolateral PFC may be needed because simulating someone’s likely state of mind entails holding this representation in mind (working memory), updating it with what is known about reality but suppressing the information about reality that does not apply in the alternative state (inhibition), and the cognitive flexibility to switch between representations (Van Hoeck, et al., 2014). However, why there might be a greater need for executive control in cognitive vs. affective ToM is not immediately obvious. A greater association between dorsolateral PFC activity and cognitive ToM is further supported by Transcranial Magnetic Stimulation (TMS) data. Here suppression of right dorsolateral PFC activity with TMS has been shown to impair nonaffective (cognitive) ToM, but not affective ToM (Kalbe, et al., 2010). The claim was made that this result showed functional independence between the two processes, but this study only targeted the functioning of a single brain region, i.e. it was not a gold-standard double dissociation.

Nevertheless, the common theme is that EP and ToM may be at least partially dissociable in this region.

'How is she showing her feelings' as identification of emotion-relevant behaviour' vs. 'why is she feeling it' as attribution of behaviours to a cause, is yet another method used to approximate the comparison of EP and ToM in fMRI studies. This methodology has revealed substantial overlap between the functional neuroanatomy for identifying emotion-relevant behaviour and making causal attributions, specifically in the inferior frontal and middle/inferior temporal gyri (Spunt \& Lieberman, 2012). Note however, that here 'EP' necessitated not just simple sensory perception, nor merely 'identifying’ the emotion. Rather, it concerned the ability to (silently) describe one part of a person's facial expression or head movement that showed how they were feeling. The authors suggested that rapid identification of expressions serves as an input to attributional processing in the mentalising system, the common middle temporal gyrus activation presumably reflecting the core 
element of understanding false-belief in cognitive and affective ToM (van Veluw \& Chance, 2014). Subsequent effective connectivity analysis in the Spunt \& Lieberman study, namely an analysis of the causal influences that neural units exert over another, showed a direct functional association between activity in the inferior frontal gyrus region and activity in core regions of the ToM system, including medial PFC (BA 8, 9 \& 10), the temporal pole and temporo-parietal junction (Spunt \& Lieberman, 2012). Importantly perhaps, comparison of the time course of activity in the inferior frontal gyrus and known ToM regions during EP demonstrated that activity in these ToM regions peaked later than that in the inferior frontal gyrus (Spunt \& Lieberman, 2012). Thus identification of emotion-relevant cues preceded ToM in time, providing support for the information processing view that EP is a necessary temporal precursor to ToM.

Evidence from neuroimaging in this section has shown that there are both common and distinct brain regions subserving EP and ToM (Chakrabarti, et al., 2006; Lee \& Siegle, 2009). In summary, affective ToM (i.e. which bears some resemblance to EP) and cognitive ToM, partly share neural correlates but can also be differentiated. We have seen that common regions include the amygdala, those regions classically associated with ToM including medial PFC and parts of the temporal lobe (temporal pole, temporo-parietal junction), with further possible sites of convergence in more lateral dorsal PFC regions and lateral parts of the temporal lobe (superior temporal sulcus, middle temporal gyrus). Differences in neuroanatomy could reflect differences in the cognitive operations required for EP and ToM, but these differences could also arise because the neuroanatomy of ToM depends on the specific type of ToM concerned (Hynes, et al., 2006), and the neuroanatomy of EP depends on which valence of emotion cues are processed (Blair, 2005).

\section{Concluding Remarks}

In this review, we have seen that the concepts of EP and ToM are often linked, and at multiple levels. At the conceptual level, two recurrent distinctions were noted. Firstly that EP 
reflects the processing of emotional information about other people whilst ToM involves processing cognitive information about people; secondly that EP reflects lower-level perceptual processes with ToM reflecting higher-level integration and inference of social information. However, when evaluating more complex emotional states (e.g. sarcasm) that have emotional and intentional components, or when the emphasis is on understanding emotion cues rather than perceiving them, these distinctions break down. One positive way in which this literature could move forward might be to pay particularly careful attention to clarity of definition when discussing EP and ToM. When both EP and ToM are discussed in a single piece of work, the author's perceived distinction between the two processes must be made absolutely clear, and right from the start. Whilst the qualifying terms ‘cognitive’ and ‘affective’ are increasingly being adopted for ToM, in future literature we recommend that for EP, alternative terms such as emotion comprehension or emotion understanding might be preferable, to better reflect the level of processing that has taken place in frequently used paradigms such as emotion labelling tasks.

At the theoretical level, models of the way EP and ToM relate to one another have proved useful in directing and organising these constructs and other related concepts. Most of these models suggest that EP precedes ToM, either via serial processing stage or separate processing streams. Concepts such as the Baron-Cohen et al. Mind-Reading System and the Information Processing System models have been particularly influential in research on the breakdown of these processes in autism and schizophrenia. One intriguing twist that has yet to be explained by current models is that if EP is important in feeding into more complex subsequent ToM processes, then why does affective ToM demonstrate an extended developmental trajectory compared to cognitive ToM (Sebastian, et al., 2012; Vetter, Weigelt, Dohnel, Smolka, \& Kliegel, 2014)?

At the neuroanatomical level, lesion studies have suggested possible overlap between EP and ToM in either the right hemisphere or PFC, but the evidence is patchy. Double-dissociations remain the (as yet elusive) gold standard for the continuation of this research. Neuroimaging data indicate overlap between the substrates of EP and ToM in dorsal PFC regions and at the temporal 
pole. Such neuroanatomical overlap has been observed not just for facial cues, but also for other modalities. The most informative research has directly compared the substrates of affective and non-affective ToM in a single study, i.e. it has compared the ability to infer state of mind based on signals from EP vs. inferences based on cues with little obvious relation to EP. The most likely possibility is that PFC and lateral temporal core regions (temporal pole and temporo-parietal junction) are activated in many EP and ToM tasks, with more specific activity in other processing regions dependent on individual task demands. Additional careful manipulations of task demands are needed to shed more light on these distinctions.

Overall, there are indications that EP and ToM share some common components, but that they might also have some distinct properties. Future research with EP and ToM tasks should clarify theoretically and experimentally, the extent to which the tasks make emotional and cognitive demands. It is likely that basic detection of emotional signals develops early in child development, and depends on a limited brain network, while classic ToM tasks demanding the understanding of beliefs is likely to develop later, and depend on more complex neural interconnections. Future research should focus on understanding the development and neural bases of emotional and theory of mind processes from perception to reasoning, to hone our models of social cognition. 


\section{References}

Abbott, J. D., Wijeratne, T., Hughes, A., Perre, D., \& Lindell, A. K. (2014). The perception of positive and negative facial expressions by unilateral stroke patients. Brain Cogn, 86, 42-54. Aboulafia-Brakha, T., Christe, B., Martory, M. D., \& Annoni, J. M. (2011). Theory of mind tasks and executive functions: a systematic review of group studies in neurology. J Neuropsychol, 5, 39-55.

Abu-Akel, A. (2003a). A neurobiological mapping of theory of mind. Brain Res Brain Res Rev, 43, 29-40.

Abu-Akel, A. (2003b). A neurobiological mapping of theory of mind. Brain Research Reviews, 43, 29-40.

Abu-Akel, A., \& Shamay-Tsoory, S. (2011). Neuroanatomical and neurochemical bases of theory of mind. Neuropsychologia, 49, 2971-2984.

Adams, R. B., Jr., \& Kleck, R. E. (2005). Effects of direct and averted gaze on the perception of facially communicated emotion. Emotion, 5, 3-11.

Adolphs, R. (2003). Cognitive neuroscience of human social behaviour. Nature Reviews Neuroscience, 4, 165-178.

Adolphs, R. (2009). The social brain: neural basis of social knowledge. Annu Rev Psychol, 60, 693716.

Adolphs, R., Baron-Cohen, S., \& Tranel, D. (2002). Impaired recognition of social emotions following amygdala damage. Journal of Cognitive Neuroscience, 14, 1264-1274.

Adolphs, R., Tranel, D., Damasio, H., \& Damasio, A. (1994). Impaired recognition of emotion in facial expressions following bilateral damage to the human amygdala. Nature, 372, 669-672.

Ahern, G. L., \& Schwartz, G. E. (1979). Differential lateralization for positive versus negative emotion. Neuropsychologia, 17, 693-698.

Apperly, I. A., Samson, D., \& Humphreys, G. W. (2005). Domain-specificity and theory of mind: evaluating neuropsychological evidence. Trends in Cognitive Sciences, 9, 572-577. 
Apperly, I. A., Samson, D., \& Humphreys, G. W. (2009). Studies of adults can inform accounts of theory of mind development. Dev Psychol, 45, 190-201.

Aziz-Zadeh, L., Sheng, T., \& Gheytanchi, A. (2010). Common premotor regions for the perception and production of prosody and correlations with empathy and prosodic ability. PLoS One, 5, e8759.

Baird, A., Dewar, B. K., Critchley, H., Dolan, R., Shallice, T., \& Cipolotti, L. (2006). Social and emotional functions in three patients with medial frontal lobe damage including the anterior cingulate cortex. Cogn Neuropsychiatry, 11, 369-388.

Baron-Cohen, S. (1994). The Mindreading System: New directions for research. Current Psychology of Cognition, 13, 724-750.

Baron-Cohen, S. (2005). The empathizing system: A revision of the 1994 model of the Mindreading system. In B. Ellis \& D. Bjorklund (Eds.), Origins of the Social Mind. New York: Guilford Press.

Baron-Cohen, S., Golan, O., \& Ashwin, E. (2009). Can emotion recognition be taught to children with autism spectrum conditions? Philosophical Transactions of the Royal Society of London. Series B, Biological Sciences, 364, 3567-3574.

Baron-Cohen, S., Jolliffe, T., Mortimore, C., \& Robertson, M. (1997). Another advanced test of theory of mind: Evidence from very-high functioning adults with autism or Asperger syndrome. Journal of Child psychology and Psychiatry, 38, 813-822.

Baron-Cohen, S., Wheelwright, S., Hill, J., Raste, Y., \& Plumb, I. (2001). The 'Reading the Mind in the Eyes' test revised version: A study with normal adults, and adults with Asperger syndrome or high-functioning autism. Journal of Child psychology and Psychiatry, 42, 241251.

Beaucousin, V., Lacheret, A., Turbelin, M. R., Morel, M., Mazoyer, B., \& Tzourio-Mazoyer, N. (2006). FMRI study of emotional speech comprehension. Cerebral Cortex, 17, 339-352. 
Beer, J. S., \& Ochsner, K. N. (2006). Social cognition: a multi level analysis. Brain Res, 1079, 98105.

Blair, R. J. (2005). Responding to the emotions of others: dissociating forms of empathy through the study of typical and psychiatric populations. Consciousness and Cognition, 14, 698-718.

Blonder, L. X., Bowers, D., \& Heilman, K. M. (1991). The role of the right hemisphere in emotional communication. Brain, 114, 1115-1127.

Bodden, M. E., Kubler, D., Knake, S., Menzler, K., Heverhagen, J. T., Sommer, J., Kalbe, E., Krach, S., \& Dodel, R. (2013). Comparing the neural correlates of affective and cognitive theory of mind using fMRI: Involvement of the basal ganglia in affective theory of mind. Adv Cogn Psychol, 9, 32-43.

Borod, J. C., Bloom, R. L., Brickman, A. M., Nakhutina, L., \& Curko, E. A. (2002). Emotional processing deficits in individuals with unilateral brain damage. Applied Neuropsychology, 9, 23-36.

Borod, J. C., Cicero, B. A., Obler, L. K., Welkowitz, J., Erhan, H. M., Santschi, C., Grunwald, I. S., Agosti, R. M., \& Whalen, J. R. (1998). Right hemisphere emotional perception: evidence across multiple channels. Neuropsychology, 12, 446-458.

Borod, J. C., Koff, E., Perlman, L. M., \& Nicholas, M. (1986). The expression and perception of facial emotion in brain-damaged patients. Neuropsychologia, 24, 169-180.

Braun, M., Traue, H. C., Frisch, S., Deighton, R. M., \& Kessler, H. (2005). Emotion recognition in stroke patients with left and right hemispheric lesion: results with a new instrument-the FEEL Test. Brain Cogn, 58, 193-201.

Brothers, L. (1995). Neurophysiology of the perception of intentions by primates. In M. S. Gazzaniga (Ed.), The Cognitive Neurosciences (pp. 1107-1115). Cambridge (MA): MIT Press.

Brothers, L. (1997). Friday's Footprint: How Society Shapes the Human Mind. New York: Oxford University Press. 
Brothers, L., \& Ring, B. (1992). A Neuroethological Framework for the Representation of Minds. Journal of Cognitive Neuroscience, 4, 107-118.

Carrington, S. J., \& Bailey, A. J. (2009). Are there theory of mind regions in the brain? A review of the neuroimaging literature. Hum Brain Mapp, 30, 2313-2335.

Chakrabarti, B., \& Baron-Cohen, S. (2006). Empathizing: neurocognitive developmental mechanisms and individual differences. Progress in Brain Research, 156, 403-417.

Chakrabarti, B., Bullmore, E., \& Baron-Cohen, S. (2006). Empathizing with basic emotions: Common and discrete neural substrates. Soc Neurosci, 1, 364-384.

Charbonneau, S., Scherzer, B. P., Aspirot, D., \& Cohen, H. (2003). Perception and production of facial and prosodic emotions by chronic CVA patients. Neuropsychologia, 41, 605-613.

Corrigan, P. W. (1997). The social perceptual deficits of schizophrenia. Psychiatry, 60, 309-326.

Cusi, A. M., Nazarov, A., Holshausen, K., Macqueen, G. M., \& McKinnon, M. C. (2012). Systematic review of the neural basis of social cognition in patients with mood disorders. $J$ Psychiatry Neurosci, 37, 154-169.

Davidson, R. J., Mednick, D., Moss, E., Saron, C., \& Schaffer, C. E. (1987). Ratings of emotion in faces are influenced by the visual field to which stimuli are presented. Brain Cogn, 6, 403411.

Decety, J. (2010). The neurodevelopment of empathy in humans. Dev Neurosci, 32, 257-267.

Decety, J., \& Lamm, C. (2007). The role of the right temporoparietal junction in social interaction: how low-level computational processes contribute to meta-cognition. Neuroscientist, 13, 580-593.

Etkin, A., Egner, T., \& Kalisch, R. (2011). Emotional processing in anterior cingulate and medial prefrontal cortex. Trends Cogn Sci, 15, 85-93.

Fossati, P. (2012). Neural correlates of emotion processing: from emotional to social brain. Eur Neuropsychopharmacol, 22 Suppl 3, S487-491.

Frith, C. D., \& Frith, U. (2006). The neural basis of mentalizing. Neuron, 50, 531-534. 
Frith, C. D., \& Frith, U. (2011). Mechanisms of social cognition. Annual Review of Psychology, 63, $1-27$.

Frith, U., \& Frith, C. D. (2003). Development and neurophysiology of mentalizing. Philosophical Transactions of the Royal Society of London. Series B, Biological Sciences, 358, 459-473. Fusar-Poli, P., Placentino, A., Carletti, F., Landi, P., Allen, P., Surguladze, S., Benedetti, F., Abbamonte, M., Gasparotti, R., Barale, F., Perez, J., McGuire, P., \& Politi, P. (2009). Functional atlas of emotional faces processing: A voxel-based meta-analysis of 105 functional magnetic resonance imaging studies. Journal of Psychiatry and Neuroscience, 34, 418-432.

Garvert, M. M., Friston, K. J., Dolan, R. J., \& Garrido, M. I. (2014). Subcortical amygdala pathways enable rapid face processing. Neuroimage, 102 Pt 2, 309-316.

Gonzalez-Liencres, C., Shamay-Tsoory, S. G., \& Brune, M. (2013). Towards a neuroscience of empathy: ontogeny, phylogeny, brain mechanisms, context and psychopathology. Neurosci Biobehav Rev, 37, 1537-1548.

Goukon, A., Noguchi, K., \& Hosokawa, T. (2007). Is processing emotional signals necessary for performance on tasks requiring understanding a "theory of mind". Psychol Rep, 101, 469474.

Grecucci, A., Giorgetta, C., Bonini, N., \& Sanfey, A. G. (2013). Reappraising social emotions: the role of inferior frontal gyrus, temporo-parietal junction and insula in interpersonal emotion regulation. Front Hum Neurosci, 7, 523.

Grecucci, A., Giorgetta, C., Van't Wout, M., Bonini, N., \& Sanfey, A. G. (2013). Reappraising the ultimatum: an fMRI study of emotion regulation and decision making. Cereb Cortex, 23, 399-410.

Green, M. F., Penn, D. L., Bentall, R., Carpenter, W. T., Gaebel, W., Gur, R. C., Kring, A. M., Park, S., Silverstein, S. M., \& Heinssen, R. (2008). Social Cognition in Schizophrenia: An 
NIMH Workshop on Definitions, Assessment, and Research Opportunities. Schizophrenia Bulletin, 34, 1211-1220.

Griffin, R., Friedman, O., Ween, J., Winner, E., Happe, F., \& Brownell, H. (2006). Theory of mind and the right cerebral hemisphere: refining the scope of impairment. Laterality, 11, 195-225.

Hamann, S. (2012). Mapping discrete and dimensional emotions onto the brain: controversies and consensus. Trends Cogn Sci, 16, 458-466.

Happe, F., Brownell, H., \& Winner, E. (1999). Acquired 'theory of mind' impairments following stroke. Cognition, 70, 211-240.

Happe, F. G. (1994). An advanced test of theory of mind: understanding of story characters' thoughts and feelings by able autistic, mentally handicapped, and normal children and adults. J Autism Dev Disord, 24, 129-154.

Hassel, S., Almeida, J. R., Frank, E., Versace, A., Nau, S. A., Klein, C. R., Kupfer, D. J., \& Phillips, M. L. (2009). Prefrontal cortical and striatal activity to happy and fear faces in bipolar disorder is associated with comorbid substance abuse and eating disorder. J Affect Disord, $118,19-27$.

Heberlein, A. S., \& Adolphs, R. (2004). Impaired spontaneous anthropomorphizing despite intact perception and social knowledge. Proc Natl Acad Sci U S A, 101, 7487-7491.

Hillis, A. E. (2014). Inability to empathize: brain lesions that disrupt sharing and understanding another's emotions. Brain, 137, 981-997.

Hynes, C. A., Baird, A. A., \& Grafton, S. T. (2006). Differential role of the orbital frontal lobe in emotional versus cognitive perspective-taking. Neuropsychologia, 44, 374-383.

Kalbe, E., Schlegel, M., Sack, A. T., Nowak, D. A., Dafotakis, M., Bangard, C., Brand, M., Shamay-Tsoory, S., Onur, O. A., \& Kessler, J. (2010). Dissociating cognitive from affective theory of mind: a TMS study. Cortex, 46, 769-780. 
Kim, J. W., Kim, J. J., Jeong, B. S., Ki, S. W., Im, D. M., Lee, S. J., \& Lee, H. S. (2005). Neural mechanism for judging the appropriateness of facial affect. Cognitive Brain Research, 25, 659-667.

Korkmaz, B. (2011). Theory of mind and neurodevelopmental disorders of childhood. Pediatr Res, 69, 101R-108R.

Kucharska-Pietura, K., \& Mortimer, A. (2013). Can antipsychotics improve social cognition in patients with schizophrenia? CNS Drugs, 27, 335-343.

Lee, K. H., \& Siegle, G. J. (2009). Common and distinct brain networks underlying explicit emotional evaluation: A meta-analytic study. Socical, Cognitive and Affective Neuroscience.

Mandal, M. K., Mohanty, A., Pandey, R., \& Mohanty, S. (1996). Emotion-specific processing deficit in focal brain-damaged patients. Int J Neurosci, 84, 87-95.

Mar, R. A. (2011). The neural bases of social cognition and story comprehension. Annu Rev Psychol, 62, 103-134.

Martin-Rodriguez, J. F., \& Leon-Carrion, J. (2010). Theory of mind deficits in patients with acquired brain injury: a quantitative review. Neuropsychologia, 48, 1181-1191.

Martin, I., \& McDonald, S. (2003). Weak coherence, no theory of mind, or executive dysfunction? Solving the puzzle of pragmatic language disorders. Brain Lang, 85, 451-466.

Mathersul, D., McDonald, S., \& Rushby, J. A. (2013). Understanding advanced theory of mind and empathy in high-functioning adults with autism spectrum disorder. J Clin Exp Neuropsychol, 35, 655-668.

Mayer, J. D., \& Salovey, P. (1997). What is emotional intelligence? . In P. Salovey \& D. J. Sluyter (Eds.), Emotional Development and Emotional Intelligence: Educational Implications. (pp. 3-31). New York, NY: Basic Books.

McCleery, J. P., Surtees, A. D., Graham, K. A., Richards, J. E., \& Apperly, I. A. (2011). The neural and cognitive time course of theory of mind. Journal of Neuroscience, 31, 12849-12854. 
McDonald, S. (2013). Impairments in social cognition following severe traumatic brain injury. $J$ Int Neuropsychol Soc, 19, 231-246.

McDonald, S., Bornhofen, C., Shum, D., Long, E., Saunders, C., \& Neulinger, K. (2006). Reliability and validity of The Awareness of Social Inference Test (TASIT): A clinical test of social perception. Disability and Rehabilitation, 28, 1529-1542.

McKinnon, M. C., Cusi, A. M., \& MacQueen, G. M. (2013). Psychological factors that may confer risk for bipolar disorder. Cogn Neuropsychiatry, 18, 115-128.

Mitchell, J. P. (2006). Mentalizing and Marr: An information processing approach to the study of social cognition. Brain Research, 1079, 66-75.

Mitchell, R. L. C., Elliott, R., Barry, M., Cruttenden, A., \& Woodruff, P. W. (2003). The neural response to emotional prosody, as revealed by functional magnetic resonance imaging. Neuropsychologia, 41, 1410-1421.

Morris, J. S., Frith, C. D., Perrett, D. I., Rowland, D., Young, A. W., Calder, A. J., \& Dolan, R. J. (1996). A differential neural response in the human amygdala to fearful and happy facial expressions. Nature, 383, 812-815.

Njomboro, P., Deb, S., \& Humphreys, G. W. (2008). Dissociation between decoding and reasoning about mental states in patients with theory of mind reasoning impairments. J Cogn Neurosci, 20, 1557-1564.

Ochsner, K. N. (2008). The social-emotional processing stream: five core constructs and their translational potential for schizophrenia and beyond. Biol Psychiatry, 64, 48-61.

Olson, I. R., Plotzker, A., \& Ezzyat, Y. (2007). The enigmatic temporal pole: a review of findings on social and emotional processing. Brain, 130, 1718-1731.

Pascual-Leone, A., Bartres-Faz, D., \& Keenan, J. P. (1999). Transcranial magnetic stimulation: studying the brain-behaviour relationship by induction of 'virtual lesions'. Philosophical Transactions of the Royal Society of London. Series B, Biological Sciences, 354, 1229-1238. 
Peelen, M. V., Atkinson, A. P., \& Vuilleumier, P. (2010). Supramodal representations of perceived emotions in the human brain. Journal of Neuroscience, 30, 10127-10134.

Pell, M. D. (2006). Judging emotion and attitudes from prosody following brain damage. Progress in Brain Research, 156, 303-317.

Phan, K. L., Wager, T., Taylor, S. F., \& Liberzon, I. (2002). Functional neuroanatomy of emotion: a meta-analysis of emotion activation studies in PET and fMRI. Neuroimage, 16, 331-348.

Phan, K. L., Wager, T. D., Taylor, S. F., \& Liberzon, I. (2004). Functional neuroimaging studies of human emotions. CNS Spectrums, 9, 258-266.

Phillips, L. H., MacLean, R. D., \& Allen, R. (2002). Age and the understanding of emotions: neuropsychological and sociocognitive perspectives. Journals of Gerontology. Series B, Psychological Sciences and Social Sciences, 57, P526-530.

Phillips, M. L. (2003). Understanding the neurobiology of emotion perception: implications for psychiatry. Br J Psychiatry, 182, 190-192.

Phillips, M. L., Drevets, W. C., Rauch, S. L., \& Lane, R. (2003). Neurobiology of emotion perception I: The neural basis of normal emotion perception. Biol Psychiatry, 54, 504-514.

Poldrack, R. A. (2011). Inferring mental states from neuroimaging data: from reverse inference to large-scale decoding. Neuron, 72, 692-697.

Poletti, M., Enrici, I., \& Adenzato, M. (2012). Cognitive and affective Theory of Mind in neurodegenerative diseases: neuropsychological, neuroanatomical and neurochemical levels. Neurosci Biobehav Rev, 36, 2147-2164.

Rogers, L. (2005). Cognitive and social advantages of having a lateralised brain. In Y. Malashichev \& A. Deckel (Eds.), Behavioral and Morphological Asymmetries in Vertebrates. Georgetown, Washington, DC: Landes Bioscience.

Ross, E. D. (2010). Cerebral localization of functions and the neurology of language: Fact versus fiction or is it something else? Neuroscientist, 16, 222-243. 
Ross, E. D., \& Monnot, M. (2011). Affective prosody: what do comprehension errors tell us about hemispheric lateralization of emotions, sex and aging effects, and the role of cognitive appraisal. Neuropsychologia, 49, 866-877.

Sabatinelli, D., Fortune, E. E., Li, Q., Siddiqui, A., Krafft, C., Oliver, W. T., Beck, S., \& Jeffries, J. (2011). Emotional perception: meta-analyses of face and natural scene processing. Neuroimage, 54, 2524-2533.

Sabbagh, M. A. (2004). Understanding orbitofrontal contributions to theory-of-mind reasoning: implications for autism. Brain and Cognition, 55, 209-219.

Said, C. P., Haxby, J. V., \& Todorov, A. (2011). Brain systems for assessing the affective value of faces. Philos Trans R Soc Lond B Biol Sci, 366, 1660-1670.

Samson, D. (2009a). Reading other people's mind: insights from neuropsychology. J Neuropsychol, 3, 3-16.

Samson, D. (2009b). Reading other people's mind: Insights from neuropsychology. Journal of Neuropsychology, 3, 3-16.

Saxe, R., Carey, S., \& Kanwisher, N. (2004). Understanding other minds: linking developmental psychology and functional neuroimaging. Annual Review of Psychology, 55, 87-124.

Sebastian, C. L., Fontaine, N. M., Bird, G., Blakemore, S. J., Brito, S. A., McCrory, E. J., \& Viding, E. (2012). Neural processing associated with cognitive and affective Theory of Mind in adolescents and adults. Soc Cogn Affect Neurosci, 7, 53-63.

Shamay-Tsoory, S. G. (2011). The neural bases for empathy. Neuroscientist, 17, 18-24.

Shamay-Tsoory, S. G., Shur, S., Barcai-Goodman, L., Medlovich, S., Harari, H., \& Levkovitz, Y. (2007). Dissociation of cognitive from affective components of theory of mind in schizophrenia. Psychiatry Research, 149, 11-23.

Shamay-Tsoory, S. G., Tomer, R., Berger, B. D., \& Aharon-Peretz, J. (2003). Characterization of empathy deficits following prefrontal brain damage: the role of the right ventromedial prefrontal cortex. Journal of Cognitive Neuroscience, 15, 324-337. 
Shamay-Tsoory, S. G., Tomer, R., Goldsher, D., Berger, B. D., \& Aharon-Peretz, J. (2004). Impairment in cognitive and affective empathy in patients with brain lesions: anatomical and cognitive correlates. J Clin Exp Neuropsychol, 26, 1113-1127.

Shany-Ur, T., \& Rankin, K. P. (2011). Personality and social cognition in neurodegenerative disease. Curr Opin Neurol, 24, 550-555.

Siegal, M., Carrington, J., \& Radel, M. (1996). Theory of mind and pragmatic understanding following right hemisphere damage. Brain and Language, 53, 40-50.

Siegal, M., \& Varley, R. (2002). Neural systems involved in "theory of mind". Nat Rev Neurosci, 3, 463-471.

Singer, T. (2006). The neuronal basis and ontogeny of empathy and mind reading: Review of literature and implications for future research. Neurosci Biobehav Rev, 30, 855-863.

Skerry, A. E., \& Saxe, R. (2014). A common neural code for perceived and inferred emotion. $J$ Neurosci, 34, 15997-16008.

Spunt, R. P., \& Lieberman, M. D. (2012). An integrative model of the neural systems supporting the comprehension of observed emotional behavior. Neuroimage, 59, 3050-3059.

Stone, V. E., Baron-Cohen, S., \& Knight, R. T. (1998). Frontal lobe contributions to theory of mind. J Cogn Neurosci, 10, 640-656.

Surian, L., \& Siegal, M. (2001). Sources of performance on theory of mind tasks in right hemisphere-damaged patients. Brain Lang, 78, 224-232.

Thirioux, B., Mercier, M. R., Blanke, O., \& Berthoz, A. (2014). The cognitive and neural time course of empathy and sympathy: an electrical neuroimaging study on self-other interaction. Neuroscience, 267, 286-306.

Tompkins, C. A., Scharp, V. L., Fassbinder, W., Meigh, K. M., \& Armstrong, E. M. (2008). A different story on "Theory of Mind" deficit in adults with right hemisphere brain damage. Aphasiology, 22, 42-61. 
Van Hoeck, N., Begtas, E., Steen, J., Kestemont, J., Vandekerckhove, M., \& Van Overwalle, F. (2014). False belief and counterfactual reasoning in a social environment. Neuroimage, 90, 315-325.

van Veluw, S. J., \& Chance, S. A. (2014). Differentiating between self and others: an ALE metaanalysis of fMRI studies of self-recognition and theory of mind. Brain Imaging Behav, 8, 24-38.

Vetter, N. C., Weigelt, S., Dohnel, K., Smolka, M. N., \& Kliegel, M. (2014). Ongoing neural development of affective theory of mind in adolescence. Soc Cogn Affect Neurosci, 9, 10221029.

Winner, E., Brownell, H., Happe, F., Blum, A., \& Pincus, D. (1998). Distinguishing lies from jokes: theory of mind deficits and discourse interpretation in right hemisphere brain-damaged patients. Brain and Language, 62, 89-106.

Witteman, J., van Ijzendoorn, M. H., van de Velde, D., van Heuven, V. J., \& Schiller, N. O. (2011). The nature of hemispheric specialization for linguistic and emotional prosodic perception: a meta-analysis of the lesion literature. Neuropsychologia, 49, 3722-3738.

Yager, J. A., \& Ehmann, T. S. (2006). Untangling social function and social cognition: a review of concepts and measurement. Psychiatry, 69, 47-68.

Yuvaraj, R., Murugappan, M., Norlinah, M. I., Sundaraj, K., \& Khairiyah, M. (2013). Review of emotion recognition in stroke patients. Dement Geriatr Cogn Disord, 36, 179-196.

Zaitchik, D., Walker, C., Miller, S., LaViolette, P., Feczko, E., \& Dickerson, B. C. (2010). Mental state attribution and the temporoparietal junction: an fMRI study comparing belief, emotion, and perception. Neuropsychologia, 48, 2528-2536.

Zgaljardic, D. J., Borod, J. C., \& Sliwinski, M. (2002). Emotional perception in unilateral stroke patients: recovery, test stability, and interchannel relationships. Appl Neuropsychol, 9, 159172. 
Table 1a

Theories proposing that there are separable 'hot' (emotion perception) and 'cold' (theory of mind) aspects of social cognition.

\begin{tabular}{llll}
\hline $\begin{array}{l}\text { Key } \\
\text { Discussion } \\
\text { Papers }\end{array}$ & $\begin{array}{l}\text { Associated Social } \\
\text { Cognition Model }\end{array}$ & Theoretical Stance & Definitions and Concepts \\
\hline (Blair, 2005) & $\begin{array}{l}\text { Tripartite empathy } \\
\text { system }\end{array}$ & $\begin{array}{l}\text { EP and ToM feed into } \\
\text { different forms of empathy }\end{array}$ & $\begin{array}{l}\text { Cognitive empathy = theory of mind. Motor empathy = mirroring motor } \\
\text { responses of observed actor e.g. their facial expression. Emotional empathy = } \\
\text { translation of expressions of emotion by the observer. }\end{array}$ \\
\hline $\begin{array}{llll}\text { (Brothers \& } \\
\text { Ring, 1992) }\end{array}$ & The social editor & $\begin{array}{l}\text { EP is only needed for one } \\
\text { particular dimension of } \\
\text { representation of other } \\
\text { minds }\end{array}$ & $\begin{array}{l}\text { 'Hot' theory of other minds registers dispositions and evaluative attitudes of } \\
\text { others. 'Cold' theory of other minds registers beliefs of others. }\end{array}$ \\
$\begin{array}{llll}\text { (L. H. Phillips, } \\
\text { et al., 2002) }\end{array}$ & $\begin{array}{l}\text { Emotion } \\
\text { understanding }\end{array}$ & $\begin{array}{l}\text { ToM and EP are both key } \\
\text { components of emotional } \\
\text { intelligence }\end{array}$ & $\begin{array}{l}\text { EP = the ability to identify others' emotions from e.g. facial information. ToM = } \\
\text { the ability to understand others' feelings or thoughts. }\end{array}$ \\
\hline $\begin{array}{l}\text { (Shamay- } \\
\text { Tsoory, et al., } \\
\text { 2004) }\end{array}$ & Empathy & $\begin{array}{l}\text { EP and ToM only overlap } \\
\text { for a particular type of ToM }\end{array}$ & $\begin{array}{l}\text { ToM can be fractionated into affective vs. cognitive. Cognitive ToM requires } \\
\text { cognitive understanding of difference between speaker's knowledge and that of } \\
\text { a listener (beliefs about beliefs). Affective ToM requires in addition an empathic } \\
\text { appreciation of the listener's emotional state (beliefs about feelings). }\end{array}$ \\
\hline
\end{tabular}

Note: Red text indicates the position of Emotion Perception in the conceptualisation. Blue text indicates the position of Theory of Mind. 
Table 1b

Theories proposing that emotion perception is one of the precursors to theory of mind.

\begin{tabular}{|c|c|c|c|}
\hline $\begin{array}{l}\text { Key Discussion } \\
\text { Papers }\end{array}$ & $\begin{array}{l}\text { Associated } \\
\text { Social } \\
\text { Cognition } \\
\text { Model }\end{array}$ & Theoretical Stance & Definitions and Concepts \\
\hline $\begin{array}{l}\text { (Baron-Cohen, } \\
\text { Golan, \& } \\
\text { Ashwin, 2009) }\end{array}$ & $\begin{array}{l}\text { The mindreading } \\
\text { system }\end{array}$ & $\begin{array}{l}\text { The more 'complex' the emotion, the } \\
\text { greater degree of ToM required to } \\
\text { decode it }\end{array}$ & $\begin{array}{l}\text { Basic emotions (happiness, sadness, fear, anger, surprise, and disgust) } \\
\text { are expressed and recognised cross-culturally. Complex emotions are } \\
\text { cognitive and belief-based rather than situation-based (e.g. troubled). } \\
\text { Social emotions necessarily depend on other people’s thoughts, } \\
\text { feelings or actions (e.g. pride). }\end{array}$ \\
\hline $\begin{array}{l}\text { (Corrigan, } \\
\text { 1997) }\end{array}$ & $\begin{array}{l}\text { Information- } \\
\text { processing } \\
\text { approach }\end{array}$ & $\begin{array}{l}\text { ToM and EP are discrete processing } \\
\text { stages that relate serially }\end{array}$ & $\begin{array}{l}\text { Perception and recognition (encoding) of emotion cues are the } \\
\text { gatekeeper stages of social information processing. Later } \\
\text { determination of protagonist goals constitutes ToM. }\end{array}$ \\
\hline $\begin{array}{l}\text { (C. D. Frith \& } \\
\text { Frith, 2006) }\end{array}$ & $\begin{array}{l}\text { The mentalising } \\
\text { system }\end{array}$ & $\begin{array}{l}\text { EP is an important source of } \\
\text { information about ToM }\end{array}$ & $\begin{array}{l}\text { Mentalising = process by which we make inferences about mental } \\
\text { states (also called 'intentional stance' and ToM). Many cues can } \\
\text { trigger mentalising. Emotions can be read from facial expressions, } \\
\text { voices, and whole-body movements. Desires, goals and intentions can } \\
\text { be read from eye gaze direction and body movements. }\end{array}$ \\
\hline (Ochsner, 2008) & $\begin{array}{l}\text { Social emotional } \\
\text { processing } \\
\text { stream }\end{array}$ & $\begin{array}{l}\text { ToM is a later constituent of the system } \\
\text { of processes that encode socially and } \\
\text { emotionally relevant inputs, represent } \\
\text { their meaning, and guide responses to } \\
\text { them. }\end{array}$ & $\begin{array}{l}\text { EP involves simple recognition judgements. ToM involves high-level } \\
\text { mental state inference. }\end{array}$ \\
\hline (Singer, 2006) & $\begin{array}{l}\text { Mentalising and } \\
\text { empathy }\end{array}$ & $\begin{array}{l}\text { EP is one of the mental states attributed } \\
\text { in ToM }\end{array}$ & $\begin{array}{l}\text { Mentalising = the attribution of desires, beliefs and intentions to } \\
\text { another person. Mental states can also include feeling and emotional } \\
\text { states. }\end{array}$ \\
\hline
\end{tabular}

Note: Red text indicates the position of Emotion Perception in the conceptualisation. Blue text indicates the position of Theory of Mind.

Table 2 
Important Theoretical Distinctions in Social Cognition tasks and Examples from each Category of Processing.

\begin{tabular}{|c|c|c|c|c|}
\hline \multirow{4}{*}{ 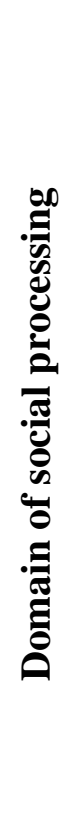 } & & $\begin{array}{c}\text { Decoding } \\
\text { Basic perception }\end{array}$ & $\begin{array}{c}\text { cognitive processing } \\
\text { Integration } \\
\text { Combining cues } \\
\end{array}$ & $\begin{array}{c}\text { Reasoning/decision-making } \\
\text { Drawing inferences }\end{array}$ \\
\hline & Affective & $\begin{array}{l}\text { EP } \\
\text { Detection of affect cues from speech or } \\
\text { nonverbal cues such as facial } \\
\text { expressions and bodily gestures. } \\
\text { Orienting of attention to emotion. }\end{array}$ & $\begin{array}{l}\text { EP } \\
\text { Multimodal emotion perception, } \\
\text { e.g. from speech and faces. }\end{array}$ & $\begin{array}{l}\text { EP } \\
\text { Emotion labelling (basic emotions), e.g. } \\
\text { of facial expressions. } \\
\text { Predicting behaviour based on emotion }\end{array}$ \\
\hline & $\begin{array}{l}\text { Cognitive (e.g. } \\
\text { intentions, beliefs) }\end{array}$ & $\begin{array}{l}\text { Eye gaze detection. } \\
\text { Biological motion detection. } \\
\text { Paralinguistic cues to intention. }\end{array}$ & $\begin{array}{l}\text { Joint attention: following another’s } \\
\text { gaze. }\end{array}$ & $\begin{array}{l}\text { ToM } \\
\text { False belief reasoning }\end{array}$ \\
\hline & $\begin{array}{l}\text { Combined (affect } \\
\text { \& cognition) }\end{array}$ & - & $\begin{array}{l}\text { Gaze x emotion processing: } \\
\text { modulating emotion perception } \\
\text { based on whether someone has } \\
\text { direct or averted gaze. }\end{array}$ & $\begin{array}{l}\text { ToM } \\
\text { Understanding faux pas, deception \& } \\
\text { sarcasm (e.g. the Strange Stories task). } \\
\text { Understanding complex emotions } \\
\text { Understanding emotion display rules }\end{array}$ \\
\hline
\end{tabular}

Note: EP = tasks in this box that have been argued to assess emotion perception. ToM = tasks in this box have been argued to assess theory of mind. 
Figure Legends

Figure 1

Key temporal and frontal regional areas of the brain relevant to the overlapping relationship between Emotion Perception and Theory of Mind (approximate location), with the Brodmann's areas from this literature where available. 